\title{
Sensitivity Analysis on Thermal Conductivity Characteristics of a Water-Based Bionanofluid Flow Past a Wedge Surface
}

\author{
Sze Qi Chan $(\mathbb{D}$, Fazlina Aman (D), and Syahira Mansur $(\mathbb{1})$ \\ Department of Mathematics and Statistics, Faculty of Applied Sciences and Technology, Universiti Tun Hussein Onn Malaysia, \\ 84000 Muar, Johor, Malaysia
}

Correspondence should be addressed to Fazlina Aman; fazlina@uthm.edu.my

Received 15 July 2018; Accepted 8 September 2018; Published 30 September 2018

Academic Editor: Filippo de Monte

Copyright (C) 2018 Sze Qi Chan et al. This is an open access article distributed under the Creative Commons Attribution License, which permits unrestricted use, distribution, and reproduction in any medium, provided the original work is properly cited.

\begin{abstract}
Thermobioconvection boundary layer flow in a suspension of water-based bionanofluid holding both nanoparticles and motile microorganisms past a wedge surface was studied. The governing nonlinear partial differential equations on reference of the Buongiorno model were transformed into a set of coupled nonlinear ordinary differential equations. Shooting technique was then used to solve the transformed nonlinear ordinary differential equations numerically. The solutions were found to be contingent on several values of the governing parameters. As highlighted, the velocity profile as well as the skin friction coefficient was affected by the pressure gradient parameter, the function of the wedge angle parameter. On the other hand, the temperature, nanoparticle concentration, and density of motile microorganism's distributions together with its corresponding local Nusselt number, local Sherwood number, and local density of the motile microorganisms change with the thermophoresis and Brownian motion parameter and so Lewis number, Schmidt number, and bioconvection Péclet number. An experimental scheme together with sensitivity analysis on the basis of Response Surface Methodology (RSM) was applied to examine the dependency of the response parameters of interest to the input parameters' change. Obviously, local Nusselt number was more sensitive towards the Brownian motion parameter when the Brownian motion parameter was at 0.2 and 0.3 . However local Sherwood number was more sensitive towards the Lewis number for all values of Brownian motion parameter. Compatibility found by comparing results between RSM and shooting technique gave confidence for the model's accuracy. The findings would provide initial guidelines for future device fabrication. Finally, the numerical results obtained were thoroughly inspected and verified with the existing values reported by some researchers.
\end{abstract}

\section{Introduction}

Nanofluid is a term first innovated by Choi and Eastman [1] showing a popular thermal conductivity suspension consisting of nominal 1-100 $\mathrm{nm}$ size particles distributed in a conventional base fluid. Since then, the research on nanofluid focusing on its thermophysical properties in the boundary layer has not stopped but increased among researchers. The interest stems from the high thermal conductivity characteristics possessed by nanofluid for heat transfer intensification which results in energy saving. Such feature is significantly crucial and essential to a wide variety of applications and has extensive future possibilities. Recent review articles recorded the uses of nanofluid in solar industry, automobile industry, mechanical industry, electronic industry, biomedical industry, heat and cool exchanger system, geothermal system, etc. $[2,3]$.
On the other hand, bionanofluid refers to water-based fluid that consists of both nanoparticles and living microorganisms. The living microorganisms are found to be denser than the water-based fluid and are likely to swim in upward direction. Bioconvection is a process of heat transfer impelled from the collective upswimming motion by the motile microorganisms due to the unstable density delamination [4-6]. The mechanism of impelling upswimming motion is closely related to the species of the living microorganisms which responds to the external stimulus. For example, oxytaxis responds to the oxygen concentration gradient, phototaxis responds to light intensity, and gyrotaxis microorganisms respond to the combination of viscous torque and gravitational pull. Bioconvection is developed as a significant mechanism in bioenergy systems and biomicrosystems $[7,8]$. It is worth mentioning that various features and aspects of bioconvection with suspension of nanoparticles have been 
conducted in the field of biomedicine and biomedical engineering. This action is aimed towards a better state of health. Therefore, the knowledge of bionanofluid thermophysical properties becomes essential when a health treatment is considered.

Wedge is a shape that is triangular in cross section. In fluid dynamic, when a surface appoints to an angle (wedge) and the free stream diverges from the surface, there would be a different fluid velocity distribution. The concept has facilitated enormous applications in the real world problem and thus gives impetus to researchers for further exploitation. Boundary layer problem of a wedge flow has large bodies of literature with Falkner and Skan [9] being the first. The extension of boundary layer flow over a shifting wedge from a static wedge has been done by Ishak et al. [10]. Michael and Boyd [11] add a slip boundary condition to the FalknerSkan equations to determine the wedge flow. Then, there are abundant amounts of studies on the problem of boundary layer flow over a static or moving wedge devoted in nanofluid with different boundary condition considered, view [12-18]. However, the study of boundary layer flow over a wedge in a fluid containing both nanoparticles and microorganisms is not fully explored. Khan et al. [19, 20] filled the gap where nanofluid flowed across a porosity wedge in the existence of living microorganism where MHD effects is taken into account. Meanwhile, Mahdy [21] explained the consequences of the microorganisms' behavior on nanofluid flow over an upright porous wedge.

Motivated by the above contributions, the authors intend to investigate the behaviors and properties of a water-based bionanofluid flow over a wedge surface by employing the simplest possible boundary conditions. This investigation is associated with the possible utilization of bionanofluid in designing microfluidic devices such as biosensors for bioapplications. Similarity transformation followed by shooting method is employed to solve the governing equations numerically. Afterwards, experimental scheme is applied together with sensitivity analysis on the basis of Response Surface Methodology (RSM) to examine the dependency of the local Nusselt number and local Sherwood number on the three governing parameters, namely, Lewis number, thermophoresis parameter, and Brownian motion parameter. This action is to assess the validity of the numerical results in order to provide a guideline in device fabrication. To the best of our knowledge, no study has been performed yet for such analysis.

\section{Mathematical Formulation}

2.1. Governing Equations. A steady two-dimensional boundary layer flow of water-based bionanofluid along the wedge surface with different configuration is considered. The problem is clearly presented through the schematic diagram as in Figure 1. The Cartesian coordinate system shows $x$ and $y$-axes are extended parallel and normal to the wedge surface with apex as the origin respectively, associated with corresponding velocity components $u$ and $v$. Taking $a$ and $c$ as constants where $u_{w}=c x^{m}$ and $u_{e}=a x^{m}$ signified to the wedge surface velocity move in the water-based bionanofluid and the free stream velocity, respectively. $T_{0}, C_{0}$, and $N_{0}$ are

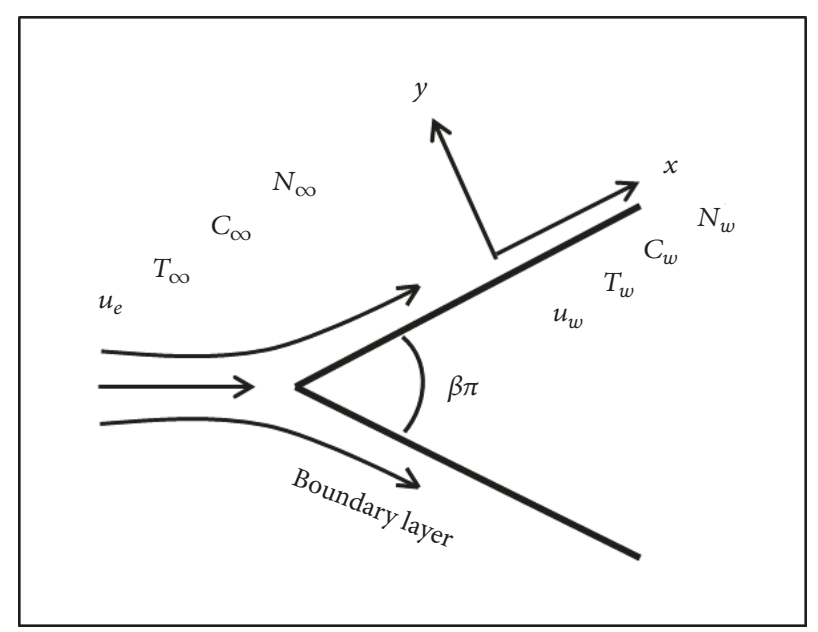

FIGURE 1: Physical model and coordination system on bionanofluid flow past a wedge surface.

the variables of the uniform temperature, nanofluid volume fraction and concentration of microorganisms, while the subscripts $w$ and $\infty$ refer to the corresponding values near the wedge surface and distance field far away from the wedge surface, respectively. Moreover, total angle of the wedge is subjected to $\beta \pi$, where $\beta$ stands for the Hartree pressure gradient expressed as the function of wedge angle parameter $m$ such that $\beta=2 m /(1+m)$.

The governing partial differential equations of continuity, momentum, thermal energy, nanoparticle concentration, and microorganisms density for the boundary layer flow of the bionanofluid are formulated as follows, on account of the Buongiorno model which includes effect of Brownian motion and thermophoresis:

$$
\begin{aligned}
& \frac{\partial u}{\partial x}+\frac{\partial v}{\partial y}=0 \\
& u \frac{\partial u}{\partial x}+v \frac{\partial u}{\partial y}=u_{e} \frac{d u_{e}}{d x}+v \frac{\partial^{2} u}{\partial y^{2}} \\
& u \frac{\partial T_{0}}{\partial x}+v \frac{\partial T_{0}}{\partial y} \\
& =\alpha \frac{\partial^{2} T_{0}}{\partial y^{2}}+\tau\left[D_{B} \frac{\partial C_{0}}{\partial y} \frac{\partial T_{0}}{\partial y}+\left(\frac{D_{T}}{T_{\infty}}\right)\left(\frac{\partial T_{0}}{\partial y}\right)^{2}\right] \\
& u \frac{\partial C_{0}}{\partial x}+v \frac{\partial C_{0}}{\partial y}=D_{B} \frac{\partial^{2} C_{0}}{\partial y^{2}}+\left(\frac{D_{T}}{T_{\infty}}\right) \frac{\partial^{2} T_{0}}{\partial y^{2}} \\
& u \frac{\partial N_{0}}{\partial x}+v \frac{\partial N_{0}}{\partial y}+\frac{\partial}{\partial y}(N \widetilde{v})=D_{n} \frac{\partial^{2} N_{0}}{\partial y^{2}}
\end{aligned}
$$

Here, $\alpha$ stands for the thermal diffusivity of nanofluid, $\tau$ represents the ratio of effective heat capacity of the nanoparticles to the base fluid, $D_{B}$ is recognized as the Brownian diffusion coefficient, and $D_{T}$ conveys the thermophoretic diffusion coefficient while $D_{n}$ signifies the diffusivity of microorganisms. Then $v$ expresses the kinematic viscosity, 
$\widetilde{v}=\left(b W_{c} /\left(C_{w}-C_{\infty}\right)\right)\left(\partial C_{0} / \partial y\right)$, where $b$ and $W_{c}$ are exemplified as the chemotaxis constant and maximum swimming speed of microorganisms.

The equations are appointed to the following boundary conditions:

$$
\begin{aligned}
v & =0, \\
u & =0, \\
T_{0} & =T_{w}, \\
C_{0} & =C_{w}, \\
N_{0} & =N_{w} \\
u & =u_{e}, \\
T_{0} & =T_{\infty}, \\
C_{0} & =C_{\infty}, \\
N_{0} & =N_{\infty}
\end{aligned}
$$$$
\text { at } y=0 \text {, }
$$

$$
\text { as } y \longrightarrow \infty \text {. }
$$

To obtain similarity solutions for the system of governing equations (1)-(5), similarity variables are indicated as below $[14,19]$ :

$$
\begin{aligned}
\eta & =\left(\frac{(1+m) u_{e}}{2 v x}\right)^{1 / 2} y, \\
\psi & =\left(\frac{2 u_{e} v x}{1+m}\right)^{1 / 2} f(\eta), \\
\theta(\eta) & =\left(\frac{T_{0}-T_{\infty}}{T_{w}-T_{\infty}}\right), \\
\phi(\eta) & =\left(\frac{C_{0}-C_{\infty}}{C_{w}-C_{\infty}}\right), \\
\chi(\eta) & =\left(\frac{N_{0}-N_{\infty}}{N_{w}-N_{\infty}}\right),
\end{aligned}
$$

where $\psi$ symbolizes the stream function introduced as $u=$ $\partial \psi / \partial y$ and $v=-\partial \psi / \partial x$ which satisfied the continuity equation (1).

By replacing (7) into (1)-(5), a set of ordinary differential equations are obtained as follows:

$$
\begin{aligned}
f^{\prime \prime \prime}+f f^{\prime \prime}+\beta\left(1-f^{\prime 2}\right) & =0, \\
\frac{1}{\operatorname{Pr}} \theta^{\prime \prime}+f \theta^{\prime}+N b \theta^{\prime} \phi^{\prime}+N t \theta^{\prime 2} & =0, \\
\phi^{\prime \prime}+L e f \phi^{\prime}+\frac{N t}{N b} \theta^{\prime \prime} & =0, \\
\chi^{\prime \prime}+S c f \chi^{\prime}-P e\left[\phi^{\prime} \chi^{\prime}+(\sigma+\chi) \phi^{\prime \prime}\right] & =0 .
\end{aligned}
$$

The boundary conditions (6) become

$$
\begin{aligned}
f(0) & =0, \\
f^{\prime}(0) & =0, \\
\theta(0) & =1, \\
\phi(0) & =1, \\
\chi(0) & =1, \\
f^{\prime}(\infty) & =1, \\
\theta(\infty) & =0, \\
\phi(\infty) & =0, \\
\chi(\infty) & =0 .
\end{aligned}
$$

Here, $\operatorname{Pr}, L e, P e$, and $S c$ represented the Prandtl number, Lewis number, bioconvection Péclet number, and Schmidt number, respectively. $\mathrm{Nb}, \mathrm{Nt}$, and $\sigma$ explained the Brownian motion parameter, thermophoresis parameter, and a dimensionless constant. They are conveyed as

$$
\begin{aligned}
\beta & =\frac{2 m}{1+m}, \\
\operatorname{Pr} & =\frac{v}{\alpha}, \\
L e & =\frac{v}{D_{B}}, \\
\operatorname{Pe} & =\frac{b W_{c}}{D_{n}}, \\
S c & =\frac{v}{D_{n}}, \\
N b & =\frac{\tau D_{B}\left(C_{w}-C_{\infty}\right)}{v}, \\
N t & =\frac{\tau D_{T}\left(T_{w}-T_{\infty}\right)}{v T_{\infty}}, \\
\sigma & =\frac{N_{\infty}}{\left(N_{w}-N_{\infty}\right)} .
\end{aligned}
$$

Skin friction coefficient $C_{f x}$, local Nusselt number $N u_{x}$, local Sherwood number $S h_{x}$, and local density of the motile microorganisms $N n_{x}$ are the parameters of interest which are stipulated as

$$
\begin{aligned}
C_{f x} & =\frac{\tau_{w}}{\rho u_{e}^{2}}, \\
N u_{x} & =\frac{x q_{w}}{k\left(T_{w}-T_{\infty}\right)}, \\
S h_{x} & =\frac{x q_{m}}{D_{B}\left(C_{w}-C_{\infty}\right)}, \\
N n_{x} & =\frac{x q_{n}}{D_{n}\left(N_{w}-N_{\infty}\right)},
\end{aligned}
$$


where $\tau_{w}, q_{w}, q_{m}$, and $q_{n}$ are, respectively, recognized as the surface shear stress, wall heat flux, wall mass flux, and wall motile microorganisms flux with the following definition:

$$
\begin{aligned}
& \tau_{w}=\mu\left(\frac{\partial u}{\partial y}\right)_{y=0}, \\
& q_{w}=-k\left(\frac{\partial T_{0}}{\partial y}\right)_{y=0}, \\
& q_{m}=-D_{B}\left(\frac{\partial C_{0}}{\partial y}\right)_{y=0}, \\
& q_{n}=-D_{n}\left(\frac{\partial N_{0}}{\partial y}\right)_{y=0} .
\end{aligned}
$$

By using (7), (13), and (14), we obtained

$$
\begin{aligned}
\operatorname{Re}_{x}^{1 / 2} C_{f x} & =\left(\frac{1+m}{2}\right)^{1 / 2} f^{\prime \prime}(0), \\
\operatorname{Re}_{x}^{-1 / 2} N u_{x} & =-\left(\frac{1+m}{2}\right)^{1 / 2} \theta^{\prime}(0), \\
\operatorname{Re}_{x}^{-1 / 2} S h_{x} & =-\left(\frac{1+m}{2}\right)^{1 / 2} \phi^{\prime}(0), \\
\operatorname{Re}_{x}^{-1 / 2} N n_{x} & =-\left(\frac{1+m}{2}\right)^{1 / 2} \chi^{\prime}(0),
\end{aligned}
$$

where $\operatorname{Re}_{x}=u_{e}(x) x / v$ denotes as the local Reynolds number, $f^{\prime \prime}(0)$ signifies the skin friction coefficient $C_{f x},-\theta^{\prime}(0)$ represents the local Nusselt number $N u_{x},-\phi^{\prime}(0)$ symbolizes the local Sherwood number $S h_{x}$, and $-\chi^{\prime}(0)$ stands for the local density of the motile microorganisms $N n_{x}$.

2.2. Experimental Scheme. In mathematics, an experiment is a computer simulation by means of a series of tests or runs designed by using computer toolbox software. This numerical experiment aims to investigate the output result of a computer code change due to the input factors and thus derive conclusions about the prominence of the factors. Response Surface Methodology (RSM) is the mathematical and statistical technique introduced by Box and Wilson [25] which is used to determine the model's uncertainty and sensitivity. RSM's main aim is to optimize the model by identifying the relationship among the output and input variables. As observed in Table 2, the local Nusselt and Sherwood numbers vary with Lewis number, thermophoresis, and Brownian motion parameter. For the purpose of identifying the correlations between the output response parameters (local Nusselt and Sherwood numbers) to the independent input parameters (Lewis number, thermophoresis, and Brownian motion parameter), mathematical experiment is designed by referring to a standard nonlinear polynomial model [26]. Redenotes the response local Nusselt number or local Sherwood number that rely on the three independent input parameters of the Lewis number, thermophoresis and Brownian motion parameter coded with symbols $A, B$, and $C$, respectively. One intercept term, three linear terms, three two-factor bilinear terms, and three squared terms are embedded in the following mathematical equation:

$$
\begin{aligned}
\operatorname{Re}= & \gamma_{0}+\gamma_{1} A+\gamma_{2} B+\gamma_{3} C+\gamma_{11} A^{2}+\gamma_{22} B^{2}+\gamma_{33} C^{2} \\
& +\gamma_{12} A B+\gamma_{13} A C+\gamma_{23} B C
\end{aligned}
$$

According to the RSM, twenty runs together with nineteen Degrees of Freedom are appropriate for selected three levels of parameters. These three levels are classified into low $(-1)$, medium (0), and high (1). Table 3 shows the three input parameters with their corresponding symbols and levels.

Central Composite Face centered design (CCF) employed in MINITAB-18 was utilized in this study to determine the experimental result. 20 runs are required for the experimental plan by referring to the expression of $2^{F}+2 F+P$, whereby $F=$ 3 is the number of factors and $P=6$ is the number of center points. The series of experimental plan is presented in Table 4.

The degree of model accuracy was predetermined by the ANOVA analysis, also named as the analysis of variance on the RSM model. ANOVA analysis is a statistical technique significance for the variability performance of particular variables' dependency whereby Degree of Freedom (DOF), sum of squares, adjusted mean square, F-value, and P-value are the computing estimators. Table 5 displays the ANOVA analysis for both the local Nusselt and the Sherwood numbers.

Sensitivity is broadly defined as the derivation of the response function with respect to the model parameters. Sensitivity analysis is the study of uncertainty criteria yielded in the output of the model apportioned by the input factors which leads to the assessment of the model's robustness. Such analysis simulates information about the key drive parameters on the model's result which then benefits engineers in designing processes.

\section{Results and Discussion}

Numerically computed solutions of the transformed ordinary differential equations (8)-(11) coupled with the boundary conditions (12) are accomplished by utilizing the shooting technique programmed in Maple18, the computer algebra software. The boundary layer thickness $\eta_{\infty}$ is set equal to 8 . In addition, the Prandtl number Pr is fixed at 6.2 (water at $25^{\circ} \mathrm{C}$ ) to ensure the survivability of the living microorganisms in the medium of conductivity. The results' veracity is verified with the results reported by previous researchers. As shown in Table 1, comparison of the values of skin friction coefficient, $f^{\prime \prime}(0)$, for different values of $\beta$ in the absence of microorganisms density equation shows a favourable agreement. Table 2 presents the values of skin friction coefficient $f^{\prime \prime}(0)$, local Nusselt number $-\theta^{\prime}(0)$, local Sherwood number $-\phi^{\prime}(0)$, and local density of the motile microorganisms $-\chi^{\prime}(0)$ for different values of $\beta, L e, N t, N b, S c, P e$, and $\sigma$. It is observed that $f^{\prime \prime}(0)$ will only be affected by $\beta$. Note that $\beta=0$ indicates a horizontal flow whereas $\beta=1$ indicates a vertical flow. $f^{\prime \prime}(0)$ increases as the value of $\beta$ increases, showing that the surface shear stress rises with wedge. The correlation between skin friction coefficient and the velocity profile on the pressure gradient parameter can be discovered in the transformed momentum equation (8). Then, by considering a constant 


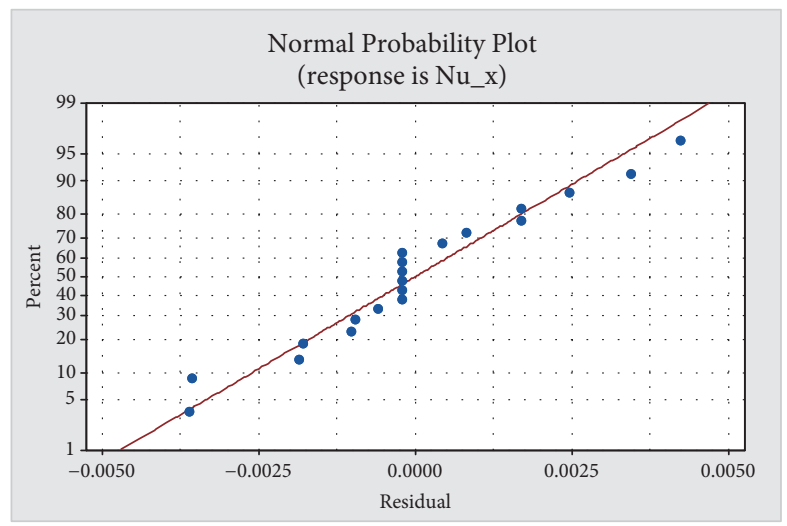

FIGURE 2: Normal probability plot of the residual for the local Nusselt number, $N u_{x}$.

TABLE 1: Comparison of the values of skin friction coefficient $f^{\prime \prime}(0)$ for different values of $\beta$ when $\operatorname{Pr}=6.2$ (water), $L e=1, S c=P e=$ $\sigma=0$, and $N t=N b \approx 0$.

\begin{tabular}{lccccc}
\hline$\beta$ & $\begin{array}{c}\text { Yih } \\
{[22]}\end{array}$ & $\begin{array}{c}\text { Kuo } \\
{[23]}\end{array}$ & $\begin{array}{c}\text { Khan and Pop } \\
{[14]}\end{array}$ & $\begin{array}{c}\text { Ali et al. } \\
{[24]}\end{array}$ & $\begin{array}{c}\text { Present } \\
\text { Results }\end{array}$ \\
\hline 0 & 0.4696 & 0.4696 & 0.4696 & 0.4946 & 0.4946 \\
$1 / 6$ & 0.6550 & - & 0.6550 & 0.6553 & 0.6550 \\
$1 / 2$ & 0.9277 & 0.9279 & 0.9277 & 0.9277 & 0.9277 \\
1 & 1.2326 & 1.2313 & 1.2326 & 1.2326 & 1.2326 \\
1.60 & - & 1.5185 & - & - & 1.5215 \\
\hline
\end{tabular}

$\beta=1 / 2$, the response parameters, $-\theta^{\prime}(0),-\phi^{\prime}(0)$, and $-\chi^{\prime}(0)$, change with the governing parameters, $L e, N t, N b, S c, P e$, and $\sigma$. On the other hand, $-\theta^{\prime}(0)$ and $-\phi^{\prime}(0)$ remain constant when $L e, N t$, and $N b$ are fixed at 1 and 0.2 , respectively. In other words, variation of the local Nusselt and Sherwood numbers are intimately related on the three governing parameters. In addition, the local density of motile microorganisms $-\chi^{\prime}(0)$ increases with $L e, N t, N b, S c, P e$, and $\sigma$ signifies the motile microorganisms performed a growing manner.

Table 5 demonstrates the ANOVA analysis to identify the correlations between the local Nusselt and Sherwood numbers to the three independent input parameters. In ANOVA analysis, F-value is the measure of data variation about the average value whereas $\mathrm{P}$-value is the probability validation of the model accuracy from the statistical viewpoint. Large F-value designates a significant result while small $\mathrm{P}$-value assigns strong support on the result's significance. Consequently, F-value is always used alongside the Pvalue to obtain strong evidence on the result's significance. Thereupon, impacts of the linear terms, two-factor bilinear terms, and squared terms for both response parameters (local Nusselt number, $N u_{x}$, and local Sherwood number, $S h_{x}$ ) are said to be statistically significant with strong evidence of large F-value and small P-value. In general, residual error is the unexplained data point by the regression line, whereas Lackof-fit exhibits when the model fails to describe the functional connectedness between the input parameters and the output response. At the same instant, normal probability plot of the residual for the local Nusselt and Sherwood number are

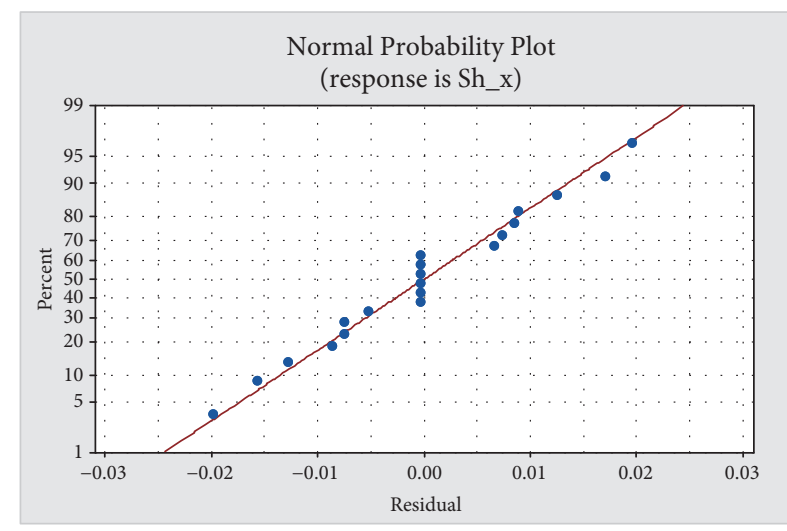

FIGURE 3: Normal probability plot of the residual for the local Sherwood number, $S h_{x}$.

displayed in Figures 2 and 3. Both plots that appear with a straight line illustrating the errors are normally distributed and so the regression model is well fitted.

The regression coefficients with its corresponding P-value for the nonlinear polynomial model in (17) for both response parameters (local Nusselt number $N u_{x}$ and local Sherwood number $S h_{x}$ ) are marked in Table 6 . It is worth mentioning that large P-value is said to be not statistically significant which means that no associate change can be detected on the output due to the change in input. Conversely, the term with small P-value $(\leq 0.05)$ that is statistically significant elsewhere can be neglected. As a result, $A, B, C, A^{2}, B^{2}, C^{2}, A B, A C$, and $B C$ are meaningful factors for $N u_{x}$ while $A, B, A^{2}, A B, A C$, and $B C$ are important terms for $S h_{x}$. Hence, mathematical equation (17) can be rewritten as

$$
\begin{aligned}
N u_{x}= & 0.2187-0.0723 A-0.0528 B-0.0785 C \\
& +0.0382 A^{2}+0.0057 B^{2}+0.0106 C^{2} \\
& +0.0089 A B+0.0035 A C+0.0147 B C, \\
S h_{x}= & 1.0180+0.3290 A+0.0896 B-0.1142 A^{2} \\
& +0.0214 A B-0.0518 A C-0.0238 B C .
\end{aligned}
$$


TABLE 2: The values of skin friction coefficient $f^{\prime \prime}(0)$, local Nusselt number $-\theta^{\prime}(0)$, local Sherwood number $-\phi^{\prime}(0)$, and local density of the motile microorganisms $-\chi^{\prime}(0)$ for different values of $\beta, L e, S c, P e, \sigma, N t$, and $N b$ when $\operatorname{Pr}=6.2$ (water).

\begin{tabular}{lllllllllll}
\hline$\beta$ & $L e$ & $N t$ & $N b$ & $S c$ & $P e$ & $\sigma$ & $f^{\prime \prime}(0)$ & $-\theta^{\prime}(0)$ & $-\phi^{\prime}(0)$ & $-\chi^{\prime}(0)$ \\
\hline 0 & & & & & & & 0.4696 & 0.4088 & 0.4163 \\
$1 / 6$ & 1 & 0.2 & 0.2 & 1 & 1 & 1 & 0.6550 & 0.4521 & 0.4259 \\
$1 / 2$ \\
1
\end{tabular}

TABLE 3: Experimental parameters and their level.

\begin{tabular}{|c|c|c|c|c|}
\hline \multirow{2}{*}{ Parameter } & \multirow{2}{*}{ Symbol } & \multicolumn{3}{|c|}{ Level } \\
\hline & & Low $(-1)$ & Medium (0) & High (1) \\
\hline$L e$ & $A$ & 1 & 3 & 5 \\
\hline$N t$ & $B$ & 0.2 & 0.3 & 0.4 \\
\hline $\mathrm{Nb}$ & C & 0.2 & 0.3 & 0.4 \\
\hline
\end{tabular}

Furthermore, the values of R-squared, $R^{2}$ and adjusted Rsquared, and $R^{2}$ - adj presented in Table 6 provide information about the goodness-of-fit of the RSM model. Notice that both $N u_{x}$ and $S h_{x}$ are reported with high $R^{2}$ and $R^{2}$ - adj values which are nearly close to $100 \%$ indicating a perfectly predicted correlation between the output response parameters and the independent input parameters.

As mentioned earlier, sensitivity is the partial derivative ratio of the response function with regard to the model parameters. Hence, sensitivity functions of local Nusselt number $N u_{x}$ and local Sherwood number $S h_{x}$ with respect to the three governing parameters, Lewis number $(A)$, thermophoresis parameter $(B)$, and Brownian motion parameter (C) based on (18) and (19) are expressed as

$$
\begin{aligned}
& \frac{\partial N u_{x}}{\partial A}=-0.0723+0.0764 A+0.0089 B+0.0035 C \\
& \frac{\partial N u_{x}}{\partial B}=-0.0528+0.0114 B+0.0089 A+0.0147 C, \\
& \frac{\partial N u_{x}}{\partial C}=-0.0785+0.0212 C+0.0035 A+0.0147 B \\
& \frac{\partial S h_{x}}{\partial A}=0.3290-0.2284 A+0.0214 B-0.0518 C
\end{aligned}
$$

$$
\begin{aligned}
& \frac{\partial S h_{x}}{\partial B}=0.0896+0.0214 A-0.0238 C \\
& \frac{\partial S h_{x}}{\partial C}=-0.0518 A-0.0238 B
\end{aligned}
$$

Using (20)-(25), the sensitivity results of the responses $\left(N u_{x}\right.$ and $\left.S h_{x}\right)$ with relation to the input governing parameters $(A$, $B$, and $C$ ) are calculated as in Table 7 . Noteworthy, a positive sensitivity value exemplifying increase of input governing parameter causes an increase in the response function and vice versa for the negative sensitivity value. Results of the sensitivity analysis have been plotted into vertical bar charts (Figures 4 and 5) for better comprehension.

As observed in Figures 4(a)-4(c), an overall trend shows sensitivity of the local Nusselt number that falls with increasing governing parameters for all values of the Brownian motion parameter. Yet, sensitivity of the local Nusselt number raises with increasing Brownian motion parameter values from 0.2 to 0.4 ( $C=-1$ to 1$)$. Also, sensitivity of the local Nusselt number towards the Brownian motion parameter is higher than the Lewis number and thermophoresis parameter for $C=-1$ and $C=0$. For the case of high Brownian motion parameter $(C=1)$, local Nusselt number seems to have a high sensitivity towards the Lewis number instead of Brownian motion and thermophoresis parameter.

Sensitivity of local Sherwood number towards different governing parameters at different values of Brownian motion parameter is shown in Figures 5(a)-5(c). In general terms, sensitivity of the local Sherwood number towards Lewis number and thermophoresis parameter increases with increasing Brownian motion parameter but the sensitivity towards Brownian motion parameter is kept constant despite the increased Brownian motion parameter. Besides, sensitivity of the local Sherwood number towards Lewis number and thermophoresis parameter shows a decreasing manner for 
TABLE 4: Design of experiments and response result.

\begin{tabular}{|c|c|c|c|c|c|c|c|c|}
\hline \multirow{2}{*}{ Runs } & \multicolumn{3}{|c|}{ Coded values } & \multicolumn{3}{|c|}{ Real values } & \multicolumn{2}{|c|}{ Response } \\
\hline & $A$ & $B$ & C & Le & $N t$ & $\mathrm{Nb}$ & $-\theta^{\prime}(0)$ & $-\phi^{\prime}(0)$ \\
\hline 1 & -1 & -1 & -1 & 1 & 0.2 & 0.2 & 0.5033 & 0.4349 \\
\hline 2 & 1 & -1 & -1 & 5 & 0.2 & 0.2 & 0.3375 & 1.1334 \\
\hline 3 & -1 & 1 & -1 & 1 & 0.4 & 0.2 & 0.3520 & 0.5917 \\
\hline 4 & 1 & 1 & -1 & 5 & 0.4 & 0.2 & 0.2150 & 1.4242 \\
\hline 5 & -1 & -1 & 1 & 1 & 0.2 & 0.4 & 0.3126 & 0.5702 \\
\hline 6 & 1 & -1 & 1 & 5 & 0.2 & 0.4 & 0.1541 & 1.1100 \\
\hline 7 & -1 & 1 & 1 & 1 & 0.4 & 0.4 & 0.2133 & 0.6803 \\
\hline 8 & 1 & 1 & 1 & 5 & 0.4 & 0.4 & 0.0970 & 1.2575 \\
\hline 9 & -1 & 0 & 0 & 1 & 0.3 & 0.3 & 0.3321 & 0.5837 \\
\hline 10 & 1 & 0 & 0 & 5 & 0.3 & 0.3 & 0.1824 & 1.2253 \\
\hline 11 & 0 & -1 & 0 & 3 & 0.2 & 0.3 & 0.2736 & 0.9257 \\
\hline 12 & 0 & 1 & 0 & 3 & 0.4 & 0.3 & 0.1758 & 1.1167 \\
\hline 13 & 0 & 0 & -1 & 3 & 0.3 & 0.2 & 0.3068 & 1.0290 \\
\hline 14 & 0 & 0 & 1 & 3 & 0.3 & 0.4 & 0.1525 & 0.9965 \\
\hline 15 & 0 & 0 & 0 & 3 & 0.3 & 0.3 & 0.2185 & 1.0176 \\
\hline 16 & 0 & 0 & 0 & 3 & 0.3 & 0.3 & 0.2185 & 1.0176 \\
\hline 17 & 0 & 0 & 0 & 3 & 0.3 & 0.3 & 0.2185 & 1.0176 \\
\hline 18 & 0 & 0 & 0 & 3 & 0.3 & 0.3 & 0.2185 & 1.0176 \\
\hline 19 & 0 & 0 & 0 & 3 & 0.3 & 0.3 & 0.2185 & 1.0176 \\
\hline 20 & 0 & 0 & 0 & 3 & 0.3 & 0.3 & 0.2185 & 1.0176 \\
\hline
\end{tabular}

TABLE 5: ANOVA analysis for the local Nusselt number, $N u_{x}$, and the local Sherwood number, $S h_{x}$.

\begin{tabular}{|c|c|c|c|c|c|}
\hline Source & DOF & Sum of squares & Adj. mean square & F-value & $\mathrm{P}$-value \\
\hline \multicolumn{6}{|l|}{$N u_{x}$} \\
\hline Model & 9 & 0.1570 & 0.0174 & 2255.96 & 0 \\
\hline Linear & 3 & 0.1424 & 0.0475 & 6140.21 & 0 \\
\hline Square & 3 & 0.0121 & 0.0040 & 521.99 & 0 \\
\hline Interaction & 3 & 0.0025 & 0.0008 & 105.67 & 0 \\
\hline Residual error & 10 & 0.0001 & 0 & - & - \\
\hline Lack-of-Fit & 5 & 0.0001 & 0 & - & - \\
\hline Pure error & 5 & 0 & 0 & - & - \\
\hline Total & 19 & 0.1570 & - & - & - \\
\hline \multicolumn{6}{|l|}{$S h_{x}$} \\
\hline Model & 9 & 1.2597 & 0.1400 & 668.44 & 0 \\
\hline Linear & 3 & 1.1625 & 0.3875 & 1850.50 & 0 \\
\hline Square & 3 & 0.0676 & 0.0226 & 107.68 & 0 \\
\hline Interaction & 3 & 0.0296 & 0.0099 & 47.13 & 0 \\
\hline Residual error & 10 & 0.0021 & 0.0002 & - & - \\
\hline Lack-of-Fit & 5 & 0.0021 & 0.0004 & - & - \\
\hline Pure error & 5 & 0 & 0 & - & - \\
\hline Total & 19 & 1.2618 & - & - & - \\
\hline
\end{tabular}


TABLE 6: Estimated regression coefficients for the local Nusselt number, $N u_{x}$, and the local Sherwood number, $S h_{x}$.

\begin{tabular}{|c|c|c|}
\hline Term & Coefficient & $\mathrm{P}$-value \\
\hline \multicolumn{3}{|l|}{$N u_{x}$} \\
\hline Constant & 0.2187 & 0 \\
\hline$A$ & -0.0723 & 0 \\
\hline$B$ & -0.0528 & 0 \\
\hline C & -0.0785 & 0 \\
\hline$A^{2}$ & 0.0382 & 0 \\
\hline$B^{2}$ & 0.0057 & 0.007 \\
\hline$C^{2}$ & 0.0106 & 0 \\
\hline$A B$ & 0.0089 & 0 \\
\hline$A C$ & 0.0035 & 0.005 \\
\hline \multirow[t]{2}{*}{$B C$} & 0.0147 & 0 \\
\hline & $R^{2}=99.95 \%$ & $R^{2}-\operatorname{adj}=99.91 \%$ \\
\hline \multicolumn{3}{|l|}{$S h_{x}$} \\
\hline Constant & 1.0180 & 0 \\
\hline$A$ & 0.3290 & 0 \\
\hline$B$ & 0.0896 & 0 \\
\hline$C$ & 0.0001 & 0.978 \\
\hline$A^{2}$ & -0.1142 & 0 \\
\hline$B^{2}$ & 0.0025 & 0.779 \\
\hline$C^{2}$ & -0.0059 & 0.512 \\
\hline$A B$ & 0.0214 & 0.002 \\
\hline$A C$ & -0.0518 & 0 \\
\hline \multirow[t]{2}{*}{$B C$} & -0.0238 & 0.001 \\
\hline & $R^{2}=99.83 \%$ & $R^{2}-\operatorname{adj}=99.68 \%$ \\
\hline
\end{tabular}

TABLE 7: Sensitivity analysis for the local Nusselt number, $N u_{x}$, and the local Sherwood number, $S h_{x}$ when $A=0$.

\begin{tabular}{cccccccc}
\hline \multirow{2}{*}{$B$} & $C$ & & \multicolumn{5}{c}{ Sensitivity } \\
& & $\partial N u_{x} / \partial A$ & $\partial N u_{x} / \partial B$ & $\partial N u_{x} / \partial C$ & $\partial S h_{x} / \partial A$ & $\partial S h_{x} / \partial B$ & 0.1134 \\
-1 & -1 & -0.0847 & -0.0789 & -0.1144 & 0.3594 & 0.0238 \\
& 0 & -0.0812 & -0.0642 & -0.0932 & 0.3076 & 0.0896 \\
\hline & 1 & -0.0777 & -0.0495 & -0.0720 & 0.2558 & 0.0658 & 0.0238 \\
0 & -1 & -0.0758 & -0.0675 & -0.0997 & 0.3808 & 0.0896 \\
& 0 & -0.0723 & -0.0528 & -0.0785 & 0.3290 & 0.0658 \\
\hline & 1 & -0.0688 & -0.0381 & -0.0573 & 0.2772 & 0.1134 & -0.0238 \\
& -1 & -0.0669 & -0.0561 & -0.0850 & 0.4022 & 0.0896 \\
& 0 & -0.0634 & -0.0414 & -0.0638 & 0.3504 & 0.0238 \\
\hline
\end{tabular}

values of $C$ from -1 to 1 . To discuss sensitivity of the local Sherwood number towards the Brownian motion parameter in details, Figure 5(a) shows similar positive sensitivity at low thermophoresis parameter for all values of Brownian motion parameter. However, zero sensitivity of local Sherwood number towards Brownian motion parameter is found at thermophoresis parameter equal to 0.3 (Figure 5(b)). Then, Figure 5(c) displays that, at high thermophoresis parameter, similar negative sensitivity of the local Sherwood number towards the Brownian motion parameter is found for all values of Brownian motion parameter.

Accuracy of RSM model is benchmarked by comparing $N u_{x}$ and $S h_{x}$ results between RSM and shooting method for $A=1$ and $C=0$. Figures 6(a)-6(b) show a good compatibility between RSM results and shooting results for the local Nusselt number and local Sherwood number. The maximum errors found between RSM and shooting results for $N u_{x}$ and $S h_{x}$ are $1.52 \%$ and $1.47 \%$, respectively. 


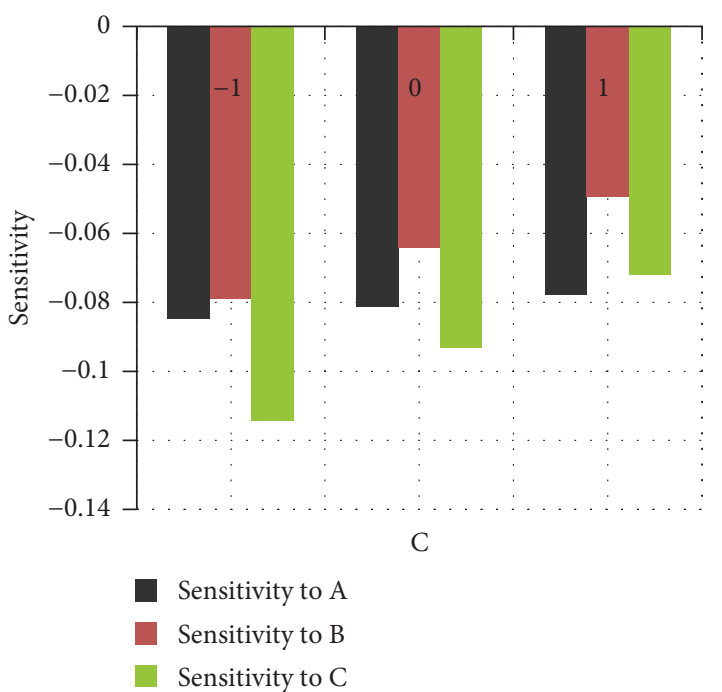

(a) Sensitivity of $\mathrm{Nu}_{-} \mathrm{x}$, for $\mathrm{A}=0$ and $\mathrm{B}=-1$

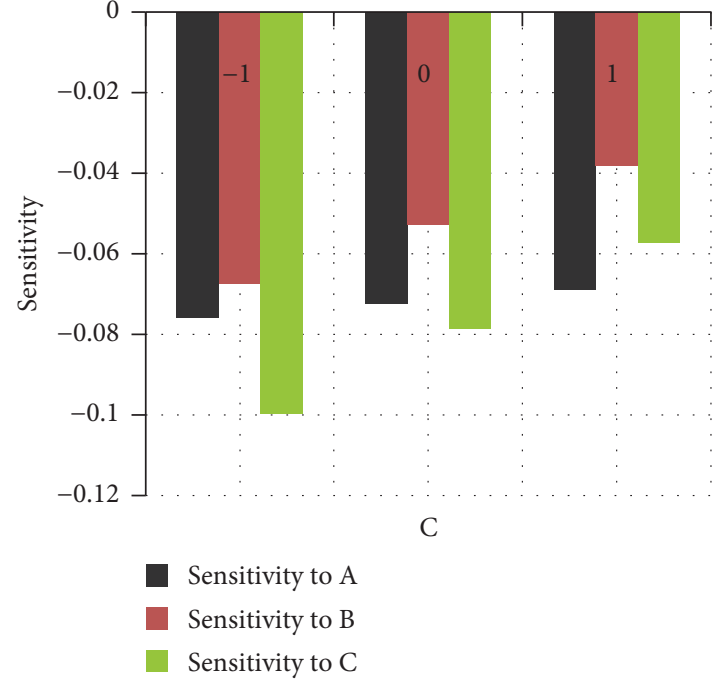

(b) Sensitivity of $\mathrm{Nu}_{-}$, for $\mathrm{A}=0$ and $\mathrm{B}=0$

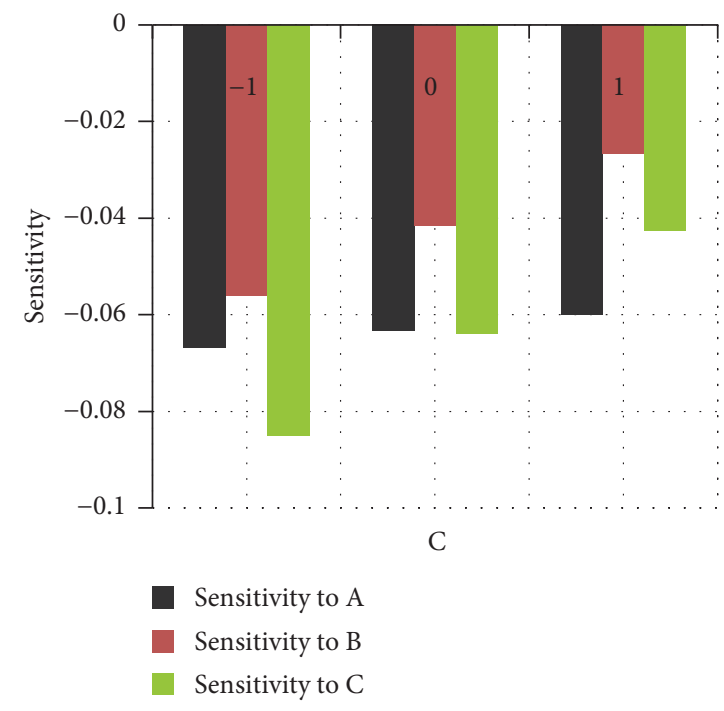

(c) Sensitivity of $\mathrm{Nu}_{-}$, for $\mathrm{A}=0$ and $\mathrm{B}=1$

FIgURE 4: Results of sensitivity analysis for the local Nusselt number, $N u_{x}$.

\section{Conclusion}

A numerical study on bioconvection boundary layer flow in a bionanofluid across a wedge surface has been carried out. Bionanofluid is believed to have a positive result on the heat and mass transfer intensification in term of stability which is crucial in designing microfluidic devices. The governing nonlinear partial differential equations are transformed to ordinary differential equations by using similarity transformation followed by the shooting technique. The numerical results then undergo a sensitivity analysis to extrapolate the dependency of the parameters of interest on the different governing parameters. The findings provided initial guidelines for future device fabrication. The findings are highlighted as follows:

(i) Wedge surface with different value of Hartree pressure gradient, $\beta$, influences the skin friction coefficient and velocity profile. (ii) The rate of heat transfer directly proportional to the local Nusselt number decreases with Lewis number, thermophoresis, and Brownian motion parameter.

(iii) The nanoparticle concentration directly proportional to the local Sherwood number increases with Lewis number, thermophoresis, and Brownian motion parameter.

(iv) Sensitivity of the local Nusselt number decreases with increasing of the three governing parameters (Lewis number, thermophoresis parameter, and Brownian motion parameter).

(v) The local Nusselt number is more sensitive towards the Brownian motion parameter by increasing the values of Brownian motion parameter from 0.2 to 0.3 . Yet, the local Nusselt number is more sensitive 


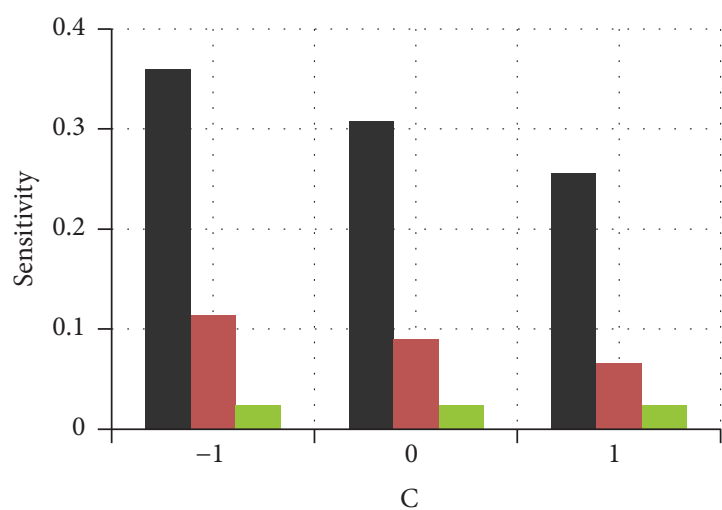

Sensitivity to A

Sensitivity to B Sensitivity to C

(a) Sensitivity of $S h_{-} \mathrm{x}$, for $\mathrm{A}=0$ and $\mathrm{B}=-1$

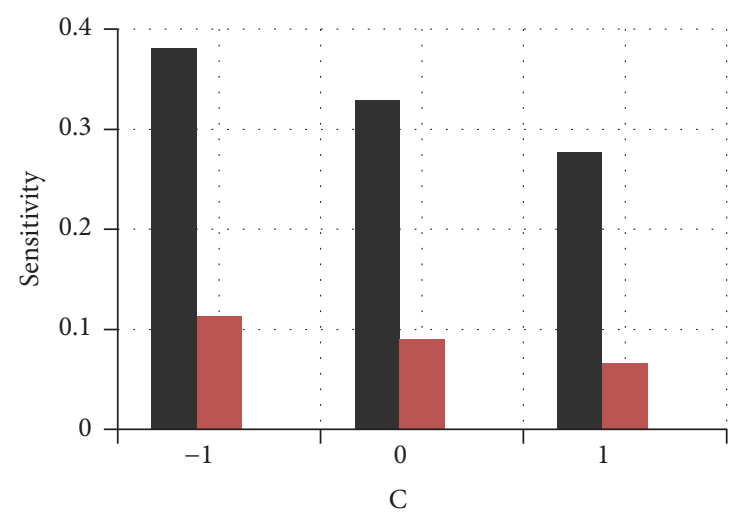

- Sensitivity to A

Sensitivity to B

Sensitivity to C

(b) Sensitivity of $S_{-}$x , for A=0 and B=0

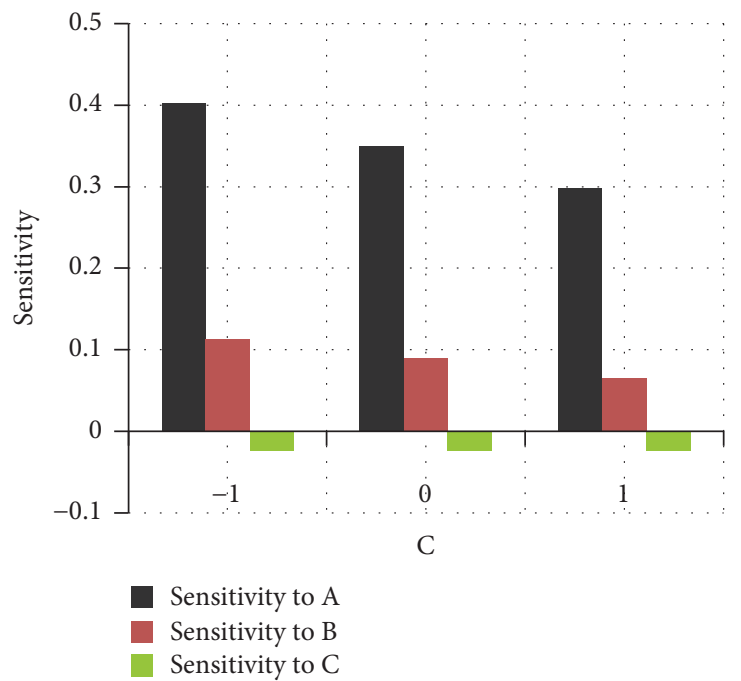

(c) Sensitivity of Sh_x, for A=0 and B=1

FIGURE 5: Results of sensitivity analysis for the local Sherwood number, $S h_{x}$.

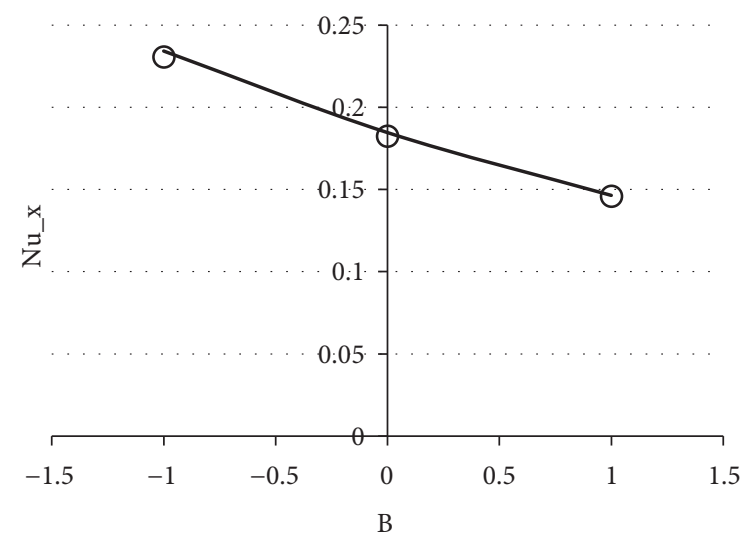

RSM

O Shooting

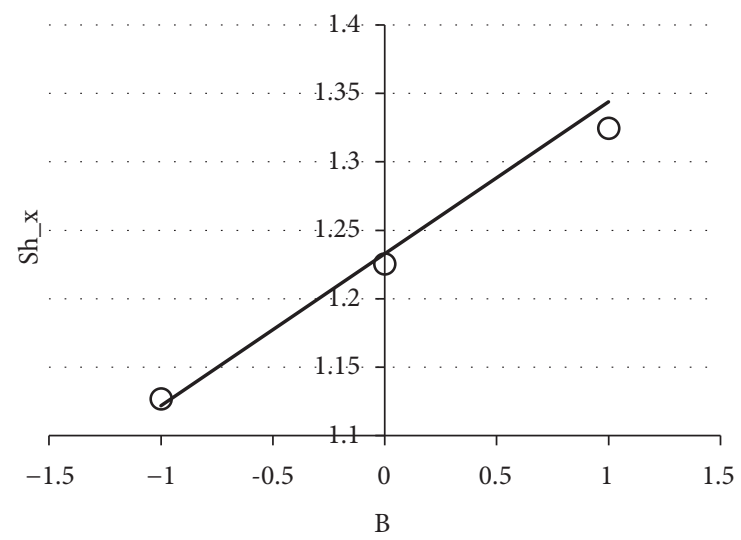

RSM

O Shooting

(a) Nu_x, for $\mathrm{A}=1$ and $\mathrm{C}=0$

(b) $\mathrm{Sh}_{\_} \mathrm{x}$, for $\mathrm{A}=1$ and $\mathrm{C}=0$

FIGURE 6: Comparison results between RSM and shooting method. 
towards Lewis number when Brownian motion parameter is high which is equal to 0.4 .

(vi) Sensitivity of the local Sherwood number increases with the increasing governing parameters, namely, Lewis number and thermophoresis parameter.

(vii) The local Sherwood number is more sensitive towards the Lewis number for three different values of thermophoresis parameter and all values of Brownian motion parameter.

\section{Data Availability}

No data were used to support this study.

\section{Conflicts of Interest}

The authors declare that there are no conflicts of interest regarding the publication of this paper.

\section{Acknowledgments}

Authors would like to express gratitude to the Research Management Centre (RMC) Universiti Tun Hussein Onn Malaysia (Project Code: GPPS-U812) and the Ministry of Higher Education, Malaysia (Project Code: FRGS-1644), for the financial support.

\section{References}

[1] S. U. S. Choi and J. A. Eastman, Enhancing thermal conductivity of fluids with nanoparticles. ASME IMECC, ASME IMECC, San Francisco, USA, 1995.

[2] D. K. Devendiran and V. A. Amirtham, "A review on preparation, characterization, properties and applications of nanofluids," Renewable \& Sustainable Energy Reviews, vol. 60, pp. 21-40, 2016.

[3] M. Jama, T. Singh, S. M. Gamaleldin et al., "Critical review on nanofluids: preparation, characterization, and applications," Journal of Nanomaterials, vol. 2016, Article ID 6717624, 22 pages, 2016.

[4] T. J. Pedley, N. A. Hill, and J. O. Kessler, "The growth of bioconvection patterns in a uniform suspension of gyrotactic micro-organisms," Journal of Fluid Mechanics, vol. 195, pp. 223237, 1988.

[5] T. J. Pedley and J. O. Kessler, "Hydrodynamic phenomena in suspensions of swimming microorganisms," Annual Review of Fluid Mechanics, vol. 24, pp. 313-358, 1992.

[6] R. N. Bearon and D. Grünbaum, "Bioconvection in a stratified environment: Experiments and theory," Physics of Fluids, vol. 18, no. 12, 2006.

[7] M. A. Bees and O. A. Croze, "Mathematics for streamlined biofuel production from unicellular algae," Biofuels, vol. 5, no. 1, pp. 53-65, 2014.

[8] J. Ravikumar and P. Goud, "Nanofluids: A promising future," Journal of Chemical and Pharmaceutical Sciences, pp. 57-61, 2014.

[9] V. M. Falkner and S. W. Skan, "Some approximate solutions of the boundary layer equations," Philosophical Magazine, vol. 12, no. 80 , pp. $865-896,1931$.
[10] A. Ishak, R. Nazar, and I. Pop, "Falkner-Skan equation for flow past a moving wedge with suction or injection," Journal of Applied Mathematics \& Computing, vol. 25, no. 1-2, pp. 67-83, 2007.

[11] M. J. Martin and I. D. Boyd, "Falkner-Skan flow over a wedge with slip boundary conditions," Journal of Thermophysics and Heat Transfer, vol. 24, no. 2, pp. 263-270, 2010.

[12] N. A. Yacob, A. Ishak, and I. Pop, "Falkner-Skan problem for a static or moving wedge in nanofluids," International Journal of Thermal Sciences, vol. 50, no. 2, pp. 133-139, 2011.

[13] N. A. Yacob, A. Ishak, R. Nazar, and I. Pop, "Falkner-Skan problem for a static and moving wedge with prescribed surface heat flux in a nanofluid," International Communications in Heat and Mass Transfer, vol. 38, no. 2, pp. 149-153, 2011.

[14] W. A. Khan and I. Pop, "Boundary Layer Flow Past a Wedge Moving in a Nanofluid," Mathematical Problems in Engineering, vol. 2013, Article ID 637285, 7 pages, 2013.

[15] R. Kandasamy, I. Muhaimin, and A. K. Rosmila, “The performance evaluation of unsteady MHD non-Darcy nanofluid flow over a porous wedge due to renewable (solar) energy," Journal of Renewable Energy, vol. 64, pp. 1-9, 2014.

[16] R. M. Kasmani, S. Sivasankaran, and Z. Siri, "Convective heat transfer of nanofluid past a wedge in the presence of heat generation/absorption with suction/injection," in Proceedings of the 21st National Symposium on Mathematical Sciences: Germination of Mathematical Sciences Education and Research Towards Global Sustainability, SKSM 21, pp. 506-511, Malaysia, November 2013.

[17] D. Srinivasacharya, U. Mendu, and K. Venumadhav, "MHD Boundary Layer Flow of a Nanofluid Past a Wedge," in Proceedings of the International Conference on Computational Heat and Mass Transfer, ICCHMT 2015, pp. 1064-1070, India, December 2015.

[18] K. Das, N. Acharya, and P. K. Kundu, "Influence of Variable Fluid Properties on Nanofluid Flow over a Wedge with Surface Slip," Arabian Journal for Science and Engineering, vol. 43, no. 5, pp. 2119-2131, 2018.

[19] U. Khan, N. Ahmed, S. T. Mohyud-Din, and B. Bin-Mohsin, "A bioconvection model for MHD flow and heat transfer over a porous wedge containing both nanoparticles and gyrotatic microorganisms," Journal of Biological Systems, vol. 24, no. 4, pp. 409-429, 2016.

[20] U. Khan, N. Ahmed, and S. T. Mohyud-Din, "Influence of viscous dissipation and Joule heating on MHD bio-convection flow over a porous wedge in the presence of nanoparticles and gyrotactic microorganisms," SpringerPlus, vol. 5, no. 1, 2016.

[21] A. Mahdy, "Gyrotactic microorganisms mixed convection nanofluid flow along an isothermal vertical wedge in porous media," International Journal of Aerospace Engineering, vol. 11, no. 4, pp. 840-850, 2017.

[22] K. A. Yih, "Uniform suction/blowing effect on forced convection about a wedge: uniform heat flux," Acta Mechanica, vol.128, no. 3-4, pp. 173-181, 1998.

[23] B.-L. Kuo, "Heat transfer analysis for the Falkner-Skan wedge flow by the differential transformation method," International Journal of Heat and Mass Transfer, vol. 48, no. 23-24, pp. 50365046, 2005.

[24] M. Ali, M. A. Alim, R. Nasrin, M. S. Alam, and M. J. H. Munshi, "Similarity Solution of Unsteady MHD Boundary Layer Flow and Heat Transfer past a Moving Wedge in a Nanofluid using the Buongiorno Model," in Proceedings of the 10th International 
Conference on Marine Technology, MARTEC 2016, pp. 407-413, Bangladesh, December 2016.

[25] G. E. P. Box and K. B. Wilson, "On the experimental attainment of optimum conditions," Journal of the Royal Statistical Society: Series B (Statistical Methodology), vol. 13, no. 1, pp. 1-45, 1951.

[26] D. C. Montgomery, Design and Analysis of Experiments, John Wiley, 8 edition, 1996. 


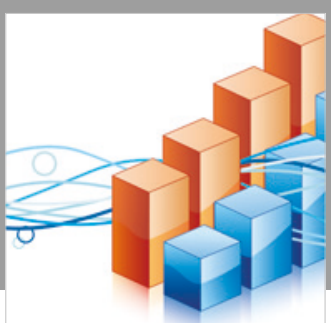

Advances in

Operations Research

\section{-n-m}
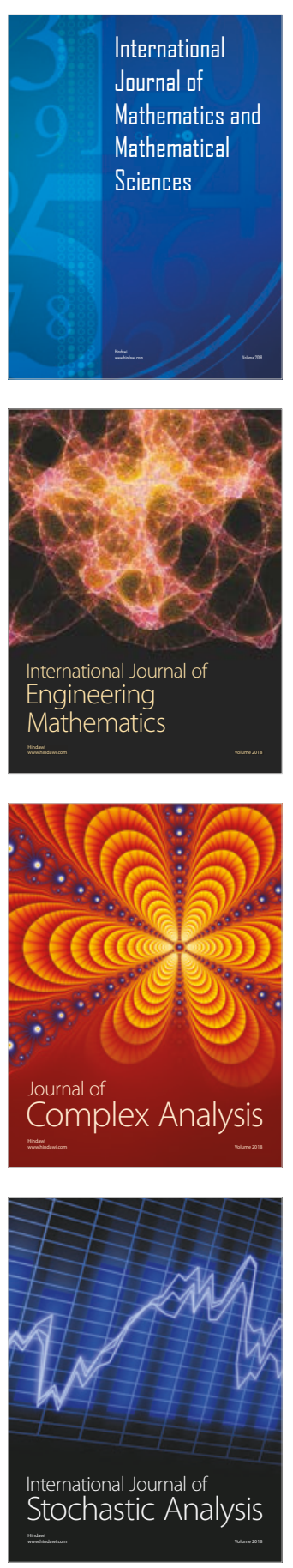
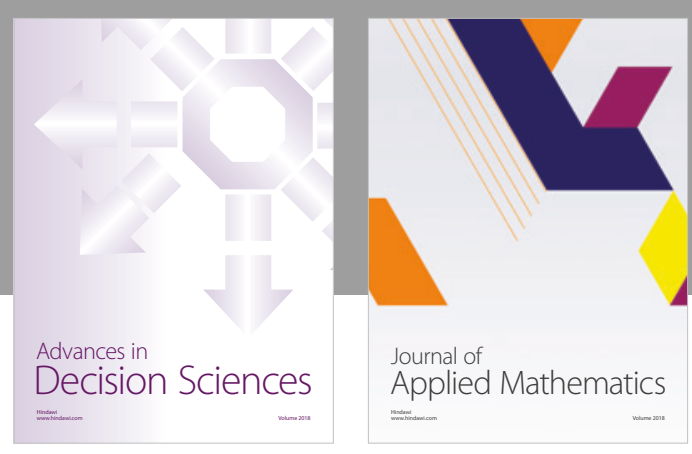

Journal of

Applied Mathematics
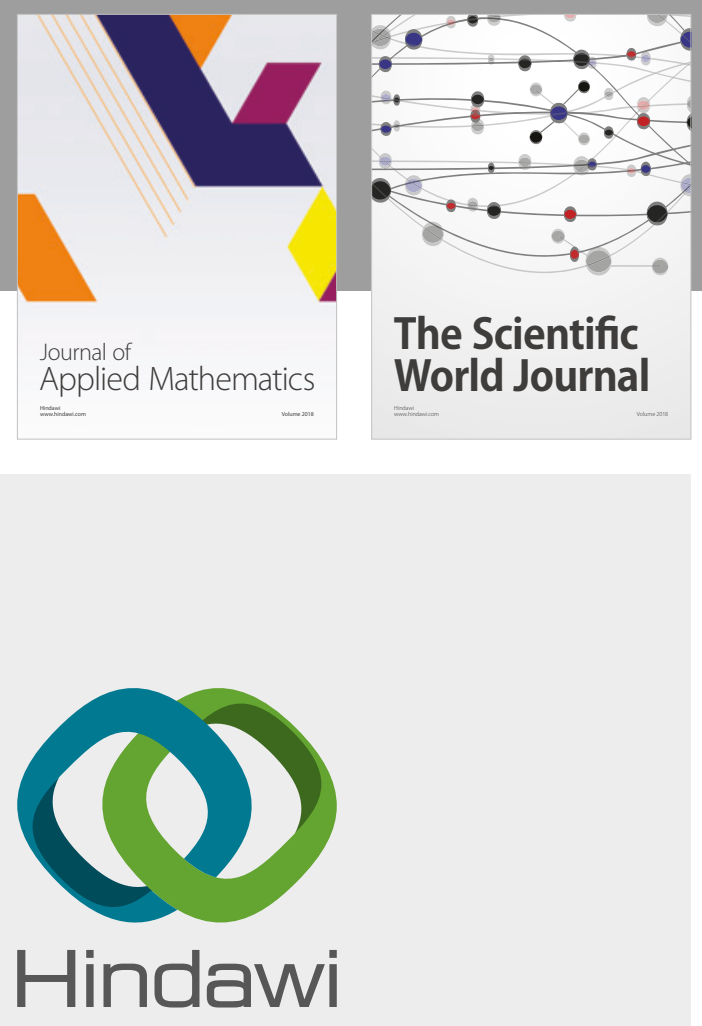

Submit your manuscripts at

www.hindawi.com

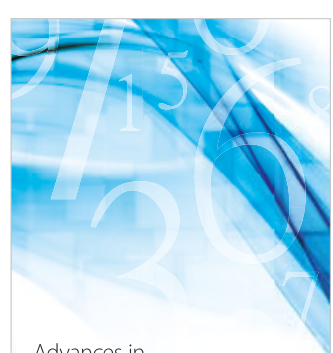

Advances in
Numerical Analysis
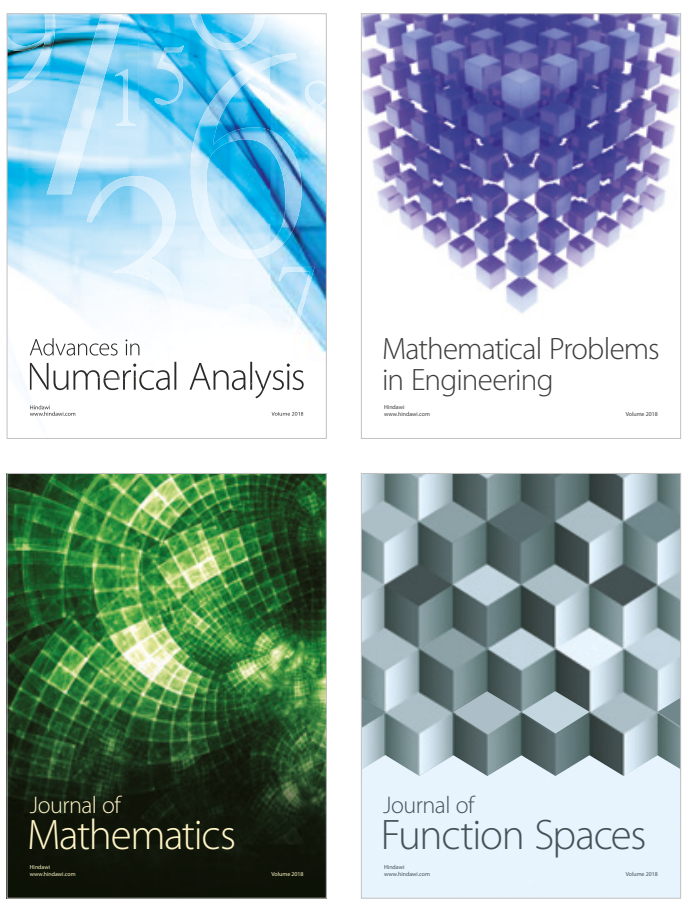

Mathematical Problems in Engineering

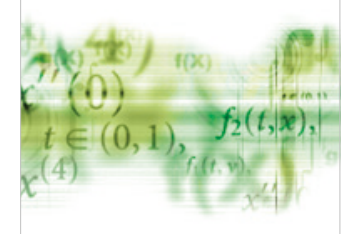

International Journal of

Differential Equations

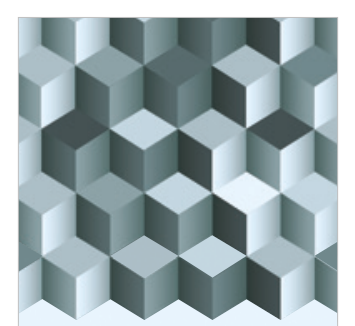

Journal of

Function Spaces
The Scientific

World Journal

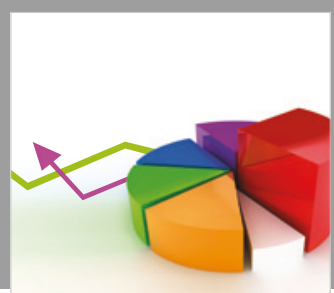

Journal of

Probability and Statistics
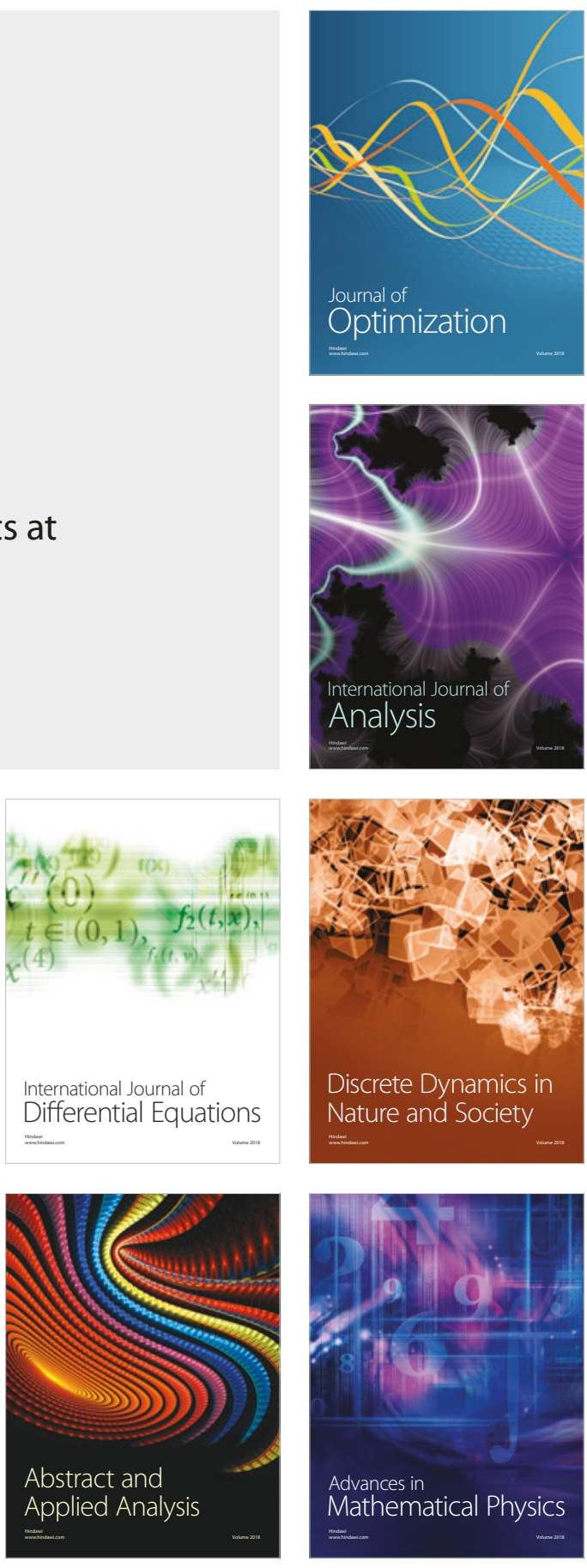